Etnográfica

Revista do Centro em Rede de Investigação em

Antropologia

vol. 18 (1) | 2014

Vol. $18(1)$

\title{
Mimetismo colonial e reprodução animal: carneiros caracul no Sudoeste angolano
}

Colonial mimesis and animal reproduction: Karakul sheep in Southwestern Angola

\section{Tiago Saraiva}

\section{(2) OpenEdition}

\section{Journals}

Edição electrónica

URL: https://journals.openedition.org/etnografica/3403

DOI: 10.4000/etnografica.3403

ISSN: 2182-2891

\section{Editora}

Centro em Rede de Investigação em Antropologia

\section{Edição impressa}

Data de publição: 1 fevereiro 2014

Paginação: 209-227

ISSN: 0873-6561

\section{Refêrencia eletrónica}

Tiago Saraiva, «Mimetismo colonial e reprodução animal: carneiros caracul no Sudoeste angolano», Etnográfica [Online], vol. 18 (1) | 2014, posto online no dia 14 março 2014, consultado o 09 fevereiro 2022. URL: http://journals.openedition.org/etnografica/3403 ; DOl: https://doi.org/10.4000/ etnografica.3403

\section{(c) (i) (9)}

Etnográfica is licensed under a Creative Commons Attribution-NonCommercial 4.0 International License. 


\section{Mimetismo colonial e reprodução animal: carneiros caracul no Sudoeste angolano}

\section{Tiago Saraiva}

Este texto explora a relação entre reprodução de colonos portugueses e reprodução de carneiros caracul no Sul de Angola. Segue-se a pista dos caraculos, desde o Sudoeste Africano sob ocupação alemã até ao deserto de Moçâmedes, usando-se o conceito de mimese para dar conta de práticas coloniais do Terceiro Império. O Posto Experimental do Caracul (PEC), fundado em 1948, serve como local de prova de tais práticas, combinando num mesmo espaço experiências de inseminação artificial de carneiros com outras mais inesperadas de sociabilidade colonial, como a organização de um "bairro indígena", a reproduzir por toda a região, que imitava uma onganda de kuvales, bem como uma casa-modelo de colono. A apropriação por Gilberto Freyre do caracul como corporização do luso-tropicalismo contribui para fazer deste carneiro um objeto de investigação privilegiado para pensar a natureza do colonialismo português.

PALAVRAS-CHAVE: caracul, Sudoeste de Angola, Gilberto Freyre, mimetismo, kuvale, colonos.

Colonial mimesis and animal reproduction: Karakul sheep in Southwestern Angola - This text explores the connected reproduction stories of Portuguese settlers and karakul sheep in Southwest Angola. It follows the karakul trail from South West Africa (SWA) under German occupation into the desert of Moçâmedes, making use of mimesis as a concept to understand colonial practices in the Third Portuguese Empire. The Karakul Experiment Station (Posto Experimental do Caracul) founded in 1948 is taken as a site for testing such practices through its combination of experiments on sheep artificial insemination as well as on colonial sociabilities. The layout of the Station, with laboratories side by side with an "indigenous village" that replicated a Kuvale onganda, was the first materialization of the new colonial society to emerge out of karakul production. The appropriation by Gilberto Freyre of karakul as embodiment of luso-tropicalism makes these sheep good things to think with in inquires on the nature of Portuguese colonialism.

KEYWORDS: karakul, Southwest Angola, Gilberto Freyre, mimesis, Kuvale, settlers.

SARAIVA, Tiago (tsaraiva@drexel.edu) - Department of History, Drexel University, USA. 
O SUDOESTE ANGOLANO OCUPA LUGAR DE DESTAQUE NAS NARRATIVAS sobre o Terceiro Império Português. ${ }^{1}$ Quer nas memórias de tom rosa que prolongam o mito de Moçâmedes e Sá da Bandeira - atuais Namibe e Lubango como cidades-modelo da colonização branca, quer nas crónicas que denunciam o caráter violento da presença portuguesa em África, a região surge como cenário privilegiado do confronto entre o nomadismo nativo e o sedentarismo colonizador. ${ }^{2}$ Desde meados do século XIX que proliferam as descrições que fizeram do planalto da Húla o destino natural de qualquer política de povoamento branco em Angola, reiterando à exaustão as semelhanças ambientais com o clima temperado da metrópole, poupando o intrépido colono às mais temidas doenças tropicais (Almeida 1912; Medeiros 1976; Castelo 2007; Bastos 2011 ). Esse mesmo clima que impediu que a zona participasse das bonanças dos ciclos da borracha ou do café prometia, em alternativa às grandes plantações, pequenas e médias propriedades exploradas por agricultores brancos dedicados à horticultura e fruticultura. As tentativas de reprodução da metrópole em África chegariam ao paroxismo em colonatos como o da Matala, construído já no princípio dos anos 50 do século XX, onde uma moderna infraestrutura de irrigação fazia o aproveitamento das águas do Cunene para garantir a aclimatação de aldeias portuguesas no trópico, santos e ranchos folclóricos incluídos (Vieira 1967; Feio 1998). Estes elementos, tão caros à revisitação da cultura popular por parte do regime salazarista (Melo 2001), acentuavam o contraste entre o apego português à terra e a mobilidade e desprendimento dos pastores nómadas locais. Às grandes manadas dos nyaneka-nkhumbi, ambó e kuvales, os colonos opunham couves, morangos e flores. Ou, dito de outra forma, o complexo do gado de Evans-Pritchard (1965 [1940]) confrontava o complexo hortofrutícola português.

Claro está que tudo é sempre mais complicado. A história da região não se conta com a substituição de um complexo por outro, da pastorícia africana

I Este ensaio é resultado do projeto "Mimetismo Colonial na Ásia e na África Lusófonas", desenvolvido no Instituto de Ciências Sociais da Universidade de Lisboa (ICS-UL) e financiado pela Fundação para a Ciência e a Tecnologia (PTDC/CS-ANT/101064/2008).

2 Entre as muitas referências possíveis, sirva como exemplo o livro da jornalista Ana Sofia Fonseca (2009) sobre a sociabilidade dos colonos brancos em Angola, feita de cinema, praia, lagostas, cerveja, corridas de carro, futebol, rádio... Sá da Bandeira e Moçâmedes são presença importante no argumento desta autora. As memórias produzidas pelos próprios retornados têm usualmente um tom mais sombrio, como por exemplo nas de Salvador de Figueiredo (2006). O fenómeno editorial associado às memórias coloniais foi assinalado por Raquel Ribeiro no jornal Público ("Os retornados estão a abrir o baú", edição de 12/08/2010). Sobre o romance dito "sério" de revisitação africana ver Gould (2008). Para a história da ocupação portuguesa do Sul de Angola são ainda indispensáveis as obras de William Gervase Clarence-Smith (1979) e de René Pélissier (1997). Ruy Duarte de Carvalho (1997, 1999), jogando com etnografia e ficção, foi sem dúvida o autor que nos últimos anos mais fez para que o Sudoeste angolano ganhasse relevância literária e científica. Cristiana Bastos (2011), no rasto das migrações madeirenses, teceu relações inesperadas entre o planalto da Huíla e outras zonas do globo. 
pela agricultura europeia. Afinal, os mais bem-sucedidos colonos de Sá da Bandeira construíram a sua fortuna a partir do comércio com pastores locais, recebendo muitas vezes gado como forma de pagamento (E. Carvalho 1974; Medeiros 1976). Durante toda a primeira metade do século XX, o gado era mantido integrado em manadas africanas para venda ulterior, ou como mera acumulação de capital. Basta estar atento a estas práticas para que a história colonial construída à volta da diferença, materializada em pares de opostos como nativo/colono, ou nómada/sedentário, perca a sua aparente linearidade. ${ }^{3}$ A partir da década de 1950 esses mesmos comerciantes de Sá da Bandeira começaram a adquirir grandes extensões de terras, com propriedades da ordem das dezenas de milhares de hectares, onde exploravam manadas próprias segundo os critérios estabelecidos pela zootecnia europeia. Mesmo os projetos estatais de irrigação ligados ao aproveitamento da bacia do Cunene passaram a insistir, a partir da década de 1960, muito mais na capacidade de produção de forragens para o gado proporcionada pela disponibilidade de água, do que na policultura destinada a sustentar pequenos povoamentos reprodutores de Trás-os-Montes e das Beiras em Angola (Feio 1998).

Se os antropólogos, na senda de Evans-Pritchard, exploraram até à exaustão as formas de organização das sociedades nativas à volta de bois - o referido complexo do gado, ou, como preferia dizer Ruy Duarte de Carvalho (1997), o "boi social" - já os historiadores não têm sido suficientemente simétricos para levar a sério a importância dos animais não humanos na construção de sociabilidades coloniais. É talvez no campo dos estudos de ciência que se encontram as propostas mais interessantes e arriscadas sobre o papel dos não humanos nas sociedades contemporâneas, resumidas por Donna Haraway (2008) com a provocação "nunca fomos humanos". O presente texto, inspirando-se na metodologia sugerida por Sarah Franklin (2007), de simplesmente seguir os itinerários das ovelhas entre nação e colónia, passando por concursos de gado e laboratórios, centra também a sua narrativa nos animais não humanos, neste caso nas ovelhas caracul, ${ }^{4}$ explorando práticas miméticas em torno destas e sugerindo o poder da mimese para iluminar a natureza das relações coloniais no Sudoeste angolano. O Posto Experimental do Caracul, fundado em 1948

3 Esta história não é um exclusivo angolano. Reviel Netz (2004), na sua história transnacional do arame farpado, chama a atenção para o facto óbvio de a vida dos cow-boys das grandes planícies dos Estados Unidos ter muito em comum com a dos índios por eles exterminados, com a organização social em torno dos búfalos a dar lugar à vida, não menos nómada, em volta do gado. Por outras palavras, a mimese não tem sido devidamente valorizada na história do Far-West.

4 “Caracul" é a versão portuguesa de karakul, termo usado pelos criadores alemães, cujo exemplo foi imitado por portugueses no Sul de Angola. Nos primeiros anos da exploração desta ovelha em Angola, os veterinários portugueses referem-se à dita como "karakul", aparecendo a denominação "caracul” de forma consistente a partir do princípio da década de 1960. Por vezes é usada também a forma "caraculo". 
no deserto de Moçâmedes, serve aqui como local de experimentação do potencial do conceito de mimese. Neste sentido, abordo o Posto Experimental do Caracul como um espaço performativo de três operações miméticas distintas: a mimese de outros impérios europeus; a mimese da sociabilidade nativa; e a mimese da sociabilidade portuguesa. Pretende-se olhar o espaço físico do posto, ovelhas incluídas, como um laboratório no qual são testadas, produzidas e reproduzidas relações coloniais estabelecidas por meio de práticas miméticas.

A atenção dada à mimese pelos estudos pós-coloniais, na senda de Homi Bhabha (1984), tem como um dos seus principais méritos o de complicar a relação colonial, antes percebida apenas em termos de "diferença", ou do "outro", dando a conhecer o potencial emancipador desses híbridos negros que mimetizam de forma exagerada (mimicry) as formas dos brancos. Aqui, mais do que reconhecer formas miméticas de emancipação, seguem-se antes os percursos mais sombrios de Michael Taussig $(1987,1993)$ e o seu recurso à mimese para dar sentido às práticas de terror associadas à extração de borracha no Sudoeste da Colômbia e no Congo Belga. ${ }^{5} \mathrm{Na}$ versão de Taussig, e em sentido oposto ao de Bhabha, o terror colonial é uma operação de mimese por parte do colonizador, tendo por base a reprodução de imagens do indígena como o selvagem que não hesita em decapitar cabeças e decepar mãos. Por mais tosca e pouco fiável que seja a imagem produzida, esta guia a ação mimética do colonizador, cuja violência derivaria assim da selvajaria indígena. Pouco importa se os nativos realmente atuam como os colonizadores os descrevem, ou se os judeus - como também indica Taussig, a partir da sua leitura de Adorno e Horkheimer - têm alguma semelhança com as caricaturas que os nazis deles faziam. Ainda segundo Taussig, para os colonizadores trata-se de ser tão selvagem e incivilizado como as imagens afirmam que índios o são, usando os alegados métodos de índios contra os próprios como única forma de relacionamento possível com raças inferiores.

Para Taussig, a mimese dá conta do poder das imagens, da forma como estas atuam no mundo. Neste texto, o Posto Experimental do Caracul é visto como materialização do tipo de mimese colonial conceptualizado por Taussig. A sua constituição física é resultado em grande parte das imagens toscas das sociedades nativas produzidas pelo cientista responsável pelo posto. Mais importante: as práticas científicas levadas a cabo no posto, ao reproduzirem ovelhas caracul pelo uso intensivo de técnicas de inseminação artificial, sugerem a relevância do papel da ciência na materialização desses processos miméticos. Cruza-se assim a literatura dos estudos de ciência sobre não humanos com a atenção dada à mimese pela antropologia, depositando-se na ciência e nas suas instituições, representadas pelo Posto Experimental, a capacidade

5 Este é um caminho semelhante ao seguido por Ricardo Roque no seu artigo sobre mimese e selvajaria neste mesmo dossiê da Etnográfica (Roque 2014). 
performativa da mimese colonial. A mimese e o seu perigoso "empobrecimento do mundo", ao simplificar o real em imagens e conduzindo às ações violentas de que fala Taussig, são, assim, percebidos como resultado de práticas científicas concretas, constituindo-se o posto como um verdadeiro laboratório de mimetismo. ${ }^{6}$

\section{VIOLÊNCIA COLONIAL TRANSNACIONAL}

Mas voltemos aos bois do Sudoeste angolano, agora pela mão de René Pélissier, um dos mais informados autores do coração das trevas português (Pélissier 1997: 267-275). No ano de 1940, um funante ${ }^{7}$ de Moçâmedes, depois de embriagar três kuvales que terão adormecido pelos efeitos da mistela oferecida pelo português, mandou marcar os seus bois como forma de resgate de dívidas anteriores. ${ }^{8}$ Após despertarem, os kuvales seguem no encalço dos seus animais, matam dois criados do português e ficam com a totalidade da manada. $\mathrm{O}$ episódio tem o seu desenlace na chegada de dois destacamentos do exército português de cerca de mil soldados e outros tantos auxiliares africanos, além de dois aviões equipados com metralhadoras, mobilizados para pôr fim aos alegados roubos de gado. Entre setembro de 1940 e fevereiro de 194l dá-se uma autêntica "caça ao kuvale" por toda a faixa semidesértica do Sul de Angola, entre o oceano e a serra da Chela, tendo sido feitos 3500 prisioneiros entre homens, mulheres e crianças, numa população kuvale que não contaria mais de 5000 indivíduos. Além das cenas de violência abjeta durante o cativeiro, incluindo matanças indiscriminadas, 600 homens terão sido enviados para as roças de cacau de São Tomé, outros tantos para a Diamang e para a colónia penitenciária de Damba, e 70 cedidos à Câmara Municipal de Moçâmedes. Quanto aos bois, a maior parte das cerca de 46.000 cabeças de gado apreendidas terá engrossado os rebanhos dos grandes proprietários brancos de Sá da Bandeira. Acusam-se os kuvales de serem ladrões inveterados de gado para no fim se lhes roubar os bois. Esta violência colonial emerge assim, tal como nos cenários de terror colonial analisados por Michael Taussig, como a resposta adequada à barbárie imaginada dos nativos.

6 A sugestão de associar ciência e empobrecimento do mundo tem uma longa tradição, da qual o praticante mais ilustre é certamente Martin Heidegger. Sobre a vasta literatura dedicada a este assunto, ver, por exemplo, Cathryn Carson (2010).

7 "Funante" - (Angola) comerciante do mato, indivíduo que vende mercadorias em localidades recônditas.

8 Citando Ruy Duarte de Carvalho, "Os Kuvale são Herero, portanto, encravados na aridez e na areia, 'residuais' e sobreviventes de uma guerra total... Os Herero de hoje provêm de populações pastoris de língua banta que terão chegado à costa ocidental da África, pelo Leste, a nível do paralelo de Benguela, e que, alcançadas as estepes que precedem o mar, flectiram para Sul, cada vez se internando mais nas bordaduras do deserto do Namibe e depois para Leste, até ao Kalahari” (Carvalho 1997: 1). 
O enredo invoca muitas outras experiências de colonização branca, e não seria difícil estabelecer comparações com as histórias violentas de fronteira na América do Norte, na Argentina, ou na Austrália (Netz 2004: 39-55; Griffiths 1997). Contudo, talvez mais interessante e pertinente do que insistir na tendência analítica da história comparativa dos diferentes impérios será seguir as relações históricas concretas que ligam o genocídio dos kuvale ao extermínio dos herero pelas tropas imperiais do Kaiser comandadas pelo general Von Trotha, entre 1904 e 1907, no território do Sudoeste Africano alemão, a atual Namíbia (Zimmerer 2005, 201 1; Gerwarth e Malinowski 2009). A continuidade com o caso angolano, além da óbvia proximidade geográfica, resulta ainda de os kuvale serem também herero ${ }^{9}$ e, ainda, de os argumentos justificativos da repressão dos kuvale parecerem decalcados dos da aniquilação dos herero.

Na Namíbia, tal como no Sudoeste de Angola, a produção e criação de caracul esteve associada às dinâmicas de violência da ocupação e colonização alemã das terras herero. Já em 1900 o missionário Peter Heinrich Brincker descrevia os herero como "uma nação submersa na imundície do gado, uma nação que vive apenas para o seu gado, cujo pensamento e vontade florescem apenas para o seu gado, um facto que é fonte constante de invejas, conflitos e infelicidades" (Stoecker 1986: 62). Enquanto a relação dos colonos alemães com o território era supostamente caracterizada por uma luta constante com a natureza, numa atitude de afirmação de força de vontade que os enraizava na terra (bodenständig), os herero não seriam mais que seres passivos, submissos à natureza e condenados à errância para satisfazer as necessidades dos seus animais. As autoridades alemãs podiam reconhecer que os herero eram de facto seminómadas. Mas enquanto a sua economia estivesse baseada na acumulação indiscriminada de gado, aqueles não deixariam de pertencer ao patamar mais baixo de civilização. A missão civilizadora alemã consistiria então num processo de solidificação progressiva de zonas de fronteira por meio do avanço da sedentarização (Stoecker 1986). Após o extermínio de $80 \%$ da população herero e de $50 \%$ dos nama, grande parte das terras foi distribuída entre os soldados alemães desmobilizados que formaram uma comunidade à volta da sua condição de criadores de ovelhas caracul (Schmokel 1985; Weigend 1985). $\mathrm{O}$ interesse por estes animais residia no valor das suas peles, que com o seu característico padrão encaracolado eram vendidas em Leipzig, Londres e Nova Iorque a preços exorbitantes, destinadas sobretudo à confeção dos luxuosos casacos de astracã (Bravenboer 2007). Além disso, a cauda adiposa fazia das ovelhas caracul animais especialmente resistentes às condições semidesérticas de grande parte do território da colónia. O papel dos caraculos na ocupação de zonas de fronteira que só tardiamente despertam a cobiça colonial está diretamente relacionado com essa sua resistência ao ambiente adverso 
aí encontrado. ${ }^{10}$ Cientistas da Universidade de Halle já tinham tentado, sem grande sucesso, aclimatizar os caraculos aos solos pobres do leste da Alemanha, com a intenção de libertarem os comerciantes de peles de Leipzig das importações de peles em bruto das estepes asiáticas. Em 1909, os mesmos cientistas seriam responsáveis por fazer chegar os caraculos ao Sudoeste Africano, prometendo criar uma fonte de riqueza a partir da exploração do deserto (Saraiva 2013). As ovelhas importadas por cientistas alemães, do Turquestão para o Sudoeste Africano, viviam em extensas propriedades de mais de 5000 hectares delimitadas por arame farpado. A sua importância crescente como fonte de rendimento (que ultrapassou a exploração de diamantes como base da economia do território) fez dos colonos brancos uma comunidade tão centrada nos animais e deles dependente, quanto os herero o eram dos seus bois (Weigend 1985). No final dos anos de 1940, mais de três décadas após a perda da colónia pela Alemanha, a atividade pecuária continuava a ocupar nada menos do que 50\% dos 40.000 brancos do território (Krogh 1955).

\section{ALEGRES CARNEIROS LUSO-TROPICAIS}

Não pretendo aqui desenvolver em detalhe o caracul social no Sudoeste Africano alemão, tema que já explorei noutro local (Saraiva 2013). Sugiro antes seguir a pista do caracul para norte, atravessando o rio Cunene, que separa Angola da Namíbia.

Após regressar de uma visita de recreio ao Sudoeste Africano em 1944, nessa altura sob controlo da União Sul-Africana, o governador da província da Huíla, o capitão Bustorff Silva, tratou de inquirir junto de Manuel dos Santos Pereira, o veterinário encarregue da estação zootécnica da Humpata na zona do planalto, sobre a possibilidade de reproduzir a experiência alemã do caracul em Angola (Pereira 1955). Este não tardou em dar uma resposta positiva, indicando o deserto de Moçâmedes - a faixa entre o oceano e o planalto recentemente pacificada após a caça ao kuvale - como a zona mais promissora para o empreendimento, não só pelas suas condições climáticas semelhantes às da estepe semidesértica do Turquestão, como pela total disponibilidade de terrenos. A admiração de Santos Pereira deixava poucas dúvidas: "O sw [Sudoeste] principalmente à custa do caracul, que constitui de longe a sua principal riqueza, conseguiu ocupar mais de dois terços da sua árida extensão territorial. Mais de 50\% dos seus 40.000 europeus e a maioria dos seus 300.000 indígenas vivem da pecuária e indústrias derivadas... [É] um símbolo e um exemplo digno de ser imitado" (Pereira 1955: 6). Tão entusiasta se revelou o veterinário que não duvidou mesmo em trocar a vida confortável que levava no planalto

10 Os esforços de colonização italiana na parte leste da Líbia, fazendo uso de ovelhas caracul, seguem o mesmo padrão da experiência alemã no Sudoeste Africano. 
pelo isolamento do deserto, assumindo-se como diretor do Posto Experimental do Caracul - o PEC - fundado em 1948 (ver figura 1). Esta seria a instituição responsável por materializar em território angolano o exemplo alemão, "digno de ser imitado".

Um diploma publicado em 1948, no mesmo ano em que se fundara o PEC, regulava a ocupação da reserva do caracul, definindo concessões de 5000 hectares - exatamente a mesma dimensão, como vimos, das alemãs. Estas concessões passariam a constituir uma fazenda particular a partir do momento em que o seu detentor ultrapassasse os 700 ovinos, aí tivesse construído uma casa de caráter definitivo e dispusesse ainda de, pelo menos, um encarregado que falasse e escrevesse português (AGU 1959). A reserva ocupava cerca de nove milhões de hectares, mais ou menos uma área equivalente a Portugal, onde se poderiam estabelecer, segundo as contas de Santos Pereira, umas 1600 famílias brancas, que se ocupariam do cuidado de cerca de dois milhões de ovelhas. Esta região semidesértica - zona totalmente por colonizar e ocupada anteriormente pelos kuvales - passaria então a ser uma fonte de divisas para a economia do império português. Segundo prometia o diretor do PEC ao inefável presidente Américo Tomás, por ocasião da I Exposição do Caracul em Lisboa, em 1959, a reserva iria cobrir grande parte das necessidades da metrópole, que, na década de 1950, importava nada menos que 90.000 peles anuais, mais de 11.000 delas de caracul. ${ }^{11}$ Mas insista-se que o significado colonial do caracul de Angola ia bem além desta contabilidade import/export. O próprio edifício do PEC no meio do deserto assim o indicia. O Posto Experimental foi construído com o intuito de se constituir como a materialização primeira de um povoamento branco exemplar, uma espécie de quinta-modelo que deveria ser replicada pelo deserto fora. O quadriculado das concessões que ocupariam toda a área reservada deveria, pois, expandir-se a partir do núcleo original do PEC (AGU 1959). ${ }^{12}$

Dada a sua relevância nos projetos de colonização do interior de Angola neste período, o PEC não tardou em ganhar o estatuto de paragem obrigatória de todo o visitante ilustre ao Sul de Angola, como seria o caso de Gilberto Freyre. Em janeiro de 1952, Freyre visitou o PEC, no seu périplo por terras portuguesas da metrópole e das colónias a convite do governo português (Freyre 1980 [1953]). Em Aventura e Rotina: Uma Viagem à Procura das Constantes Portuguesas de Carácter e Aç̧ão, livro em forma de diário de viagem que recolhe as impressões e reflexões do antropólogo pernambucano, este invoca a visão "inesquecível... [do] posto que junta aos currais um laboratório moderníssimo.

11 Tais números sugerem a necessidade urgente de um estudo sobre o consumo de luxo no Portugal do Estado Novo.

12 São múltiplos os casos em que as estações experimentais assumiram este papel de posto avançado da colonização. Ver, sobre este assunto, sobretudo os artigos de Chritophe Bonneuil (1999, 2000). 


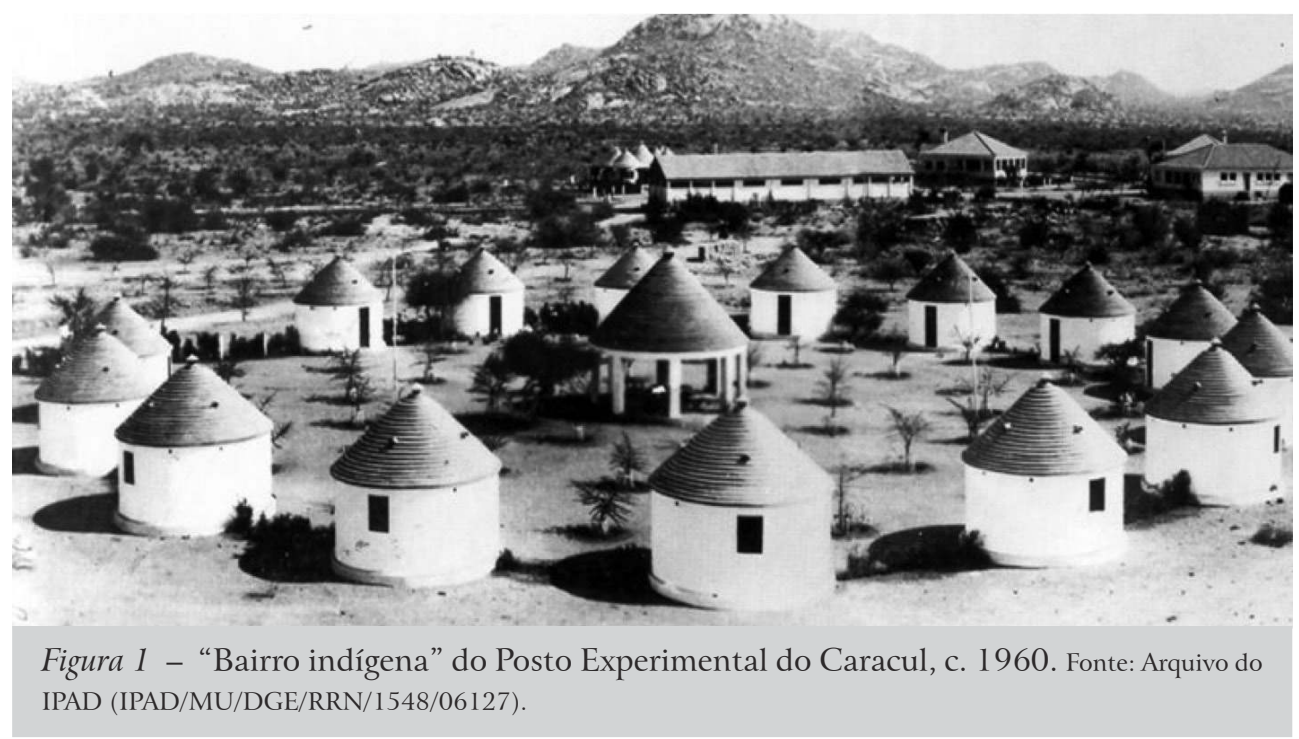

Nas pastagens, milhares de cabeças de gado já adaptadas ao deserto. Os cruzamentos acabaram pela revelação de um tipo como que ecológico de carneiro. Carneiro do deserto" (Freyre 1980 [1953]: 374). Cabe aqui citar ainda o final do livro, no qual Gilberto Freyre refere a sua entrega ao Presidente do Brasil da oferta do Presidente da República Portuguesa de um cofre com uma rara e velha edição de Os Lusíadas, de "tal modo composto com diamantes de Angola, marfim de Moçambique, ouro da Guiné, prata de Portugal, pérolas do Oriente português, madeira de Cabo Verde - que todo ele irradia Portugal, o Ultramar português, o carinho pan-lusitano pelo Brasil" (Freyre 1980 [1953]: 444). $\mathrm{O}$ dito cofre ia forrado a nada mais, nada menos que pele de caracul de Angola. ${ }^{13}$ Vale, pois, a pena explorar esta inesperada referência de Freyre ao caracul, analisando-a como materialização das supostas "constantes portuguesas de caráter e ação" por ele avançadas. Importa, por outras palavras, investigar a natureza luso-tropical do caracul.

Para Freyre, o "carneiro ecológico" era o resultado do cruzamento levado a cabo pelos melhoradores zootécnicos das espécies introduzidas pelos portugueses com espécies locais, formando um híbrido que demonstrava mais uma vez a capacidade permanente de adaptação lusitana às condições encontradas nos trópicos - a tal constante de ação que obcecava Freyre. Um carneiro híbrido merecia do brasileiro elogios semelhantes ao das plantas do Jardim do Ultramar de Lisboa, que haviam levado a cabo; escrevia:

13 Devo esta referência ao caracul na obra de Gilberto Freyre à generosidade intelectual da Cláudia Castelo. 
"[uma] revolução no plano da sociologia da vida vegetal... Novos ajustamentos ecológicos foram conseguidos. É certo que quase sempre tiveram essas aventuras de transplantação a favorecê-los, no sentido como que pantropical da vida, que foi de início, e continua hoje, o principal na atividade portuguesa no ultramar" (Freyre 1980 [1953]: 19-20).

Estamos portanto perante práticas de cruzar animais e plantas que têm um correlato direto com o pantropicalismo alegadamente característico da forma portuguesa de estar no mundo. Num inspirado e inspirador texto de Cristiana Bastos, o "alegre luso-tropicalismo" de Freyre é lido em contraponto aos Tristes Trópicos de Lévi-Strauss, tomando o primeiro como uma tentativa de superar a "alteridade e contradição, dualismo, oposição", características da antropologia dominada pela figura do segundo (Bastos 1998: 420). ${ }^{14}$ A proposta de Bastos não é, claro está, retomar o gesto de Freyre para ver continuidades onde outros só querem ver alteridade. A autora convida-nos antes a revisitar os "ícones e temas" do luso-tropicalismo, recomendando distância crítica em relação "ao mito do não racismo e do grande humanismo dos Portugueses" e propondo um ambicioso programa de trabalhos em torno dessa tão peculiar iconografia feita de "soldados de Albuquerque casando com indianas" e "nativos sortidos de mãos dadas e sorrisos nos lábios" (Bastos 1998: 431 ). O caracul, cuja pele aconchega o relicário luso-tropicalista oferecido por Américo Tomás a Getúlio Vargas - com Gilberto Freyre como oficiante do ritual -, pertence de pleno direito à família desses ícones que integram o programa de trabalhos proposto por Bastos no final dos anos de 1990.

\section{TRISTES CARACULOS PURO-SANGUE}

Olhemos então mais de perto para o carneiro do deserto, para tentar superar as visões de Freyre sobre a natureza do colonialismo português. Do que já se disse, convém recordar que o caracul de Angola foi construído em cima da erradicação dos kuvale e das suas manadas da faixa desértica do Sudoeste angolano. Talvez mais grave aos olhos do luso-tropicalismo de Freyre, esta violência portuguesa imitava as iniciativas alemãs mais a sul, na atual Namíbia, das quais a alegria "luso-tropical" estava certamente ausente. Além disso, um olhar mais atento às próprias práticas de melhoramento animal levadas a cabo no PEC revela uma história muito diferente dos benignos cruzamentos e miscigenações tão caros a Freyre; revela também, afinal, uma história colonial de purificação e violência.

14 Bastos não sugere que a obra de Freyre seja uma resposta direta à de Lévi-Strauss, até porque Aventura e Rotina é anterior a Tristes Trópicos. 
Qualquer exploração de caraculos tinha de começar por garantir um macho reprodutor, cuja pureza era certificada pelos grandes centros mundiais de genética animal, como a Universidade de Halle na Alemanha, até ao eclodir da Segunda Guerra Mundial, ou o United States Department of Agriculture em Washington, DC, nos anos do pós-guerra (Saraiva 2013). Foi justamente a partir dos reprodutores certificados de Halle que a exploração de caraculos no Sudoeste Africano alemão se desenvolveu. Apenas os dispendiosos reprodutores puros, de linhagem certificada, garantiam os padrões de pele rizados que faziam dos casacos de astracã um objeto de consumo de luxo. Estes reprodutores não eram fáceis de obter, com os grandes países produtores como o Sudoeste Africano ou a União Soviética proibindo a sua venda para evitar futura concorrência.

Uma exploração de caraculos só era viável cruzando o caro reprodutor com alguma ovelha local barata, pois uma exploração toda feita em pureza seria incomportável do ponto de vista comercial. Felizmente, os geneticistas haviam já demonstrado a dominância do pelo rizado, o que possibilitava levar a cabo os ditos cruzamentos. O tal carneiro do deserto, a que se referia Freyre, era o resultado do cruzamento do reprodutor puro-sangue com raças locais, uma prática que exigia o registo cuidadoso de cada um dos cruzamentos e o controlo das cobrições, garantindo sempre que a fecundação fosse feita por um macho puro e não por qualquer híbrido (Saraiva 2013). Registos e controlos faziam do negócio do caracul um exclusivo branco, pondo-se completamente de lado a hipótese de alguma vez um nativo poder levar a cabo a gestão científica de um rebanho caracul. Não estamos então perante uma simples mistura do europeu com o tropical, do estrangeiro com o local, ou do colonizador com o nativo. Há, neste caso, uma necessidade imperiosa de garantir e manter a pureza do colonizador - o carneiro caracul certificado - para produzir cordeiros com as peles rizadas tão do agrado das habituées dos salões de chá lisboetas. Ou, dito de outra forma, a produção do carneiro colonial, capaz de sustentar os bravos colonos portugueses, dependia da vigilância ativa da pureza dos reprodutores vindos da Europa ou dos Estados Unidos. A pureza não podia desaparecer nunca num feliz processo de aclimatação.

É revelador que uma das tarefas essenciais do PEC fosse a guarda e distribuição dessa pureza: não só os machos reprodutores eram emprestados gratuitamente aos donos das várias concessões, como o próprio Santos Pereira (o veterinário responsável pelo posto) era quem desenvolvia os maiores esforços para promover a inseminação artificial como forma eficiente de distribuir os genes dos seus caraculos puros por toda a área de reserva do caracul. Se as fêmeas híbridas, resultantes dos diferentes cruzamentos, podiam ser inseminadas com sémen dos reprodutores puros, já todos os machos híbridos tinham de ser sacrificados antes de atingir a idade de reprodução, de forma a não contaminarem o rebanho e a não comprometer a viabilidade de toda a 
exploração. ${ }^{15} \mathrm{Na}$ verdade, todos os cordeiros destinados à produção de peles eram sacrificados, o mais tardar, ao segundo dia após a nascença, momento depois do qual o padrão rizado da pele se desfazia, perdendo esta a quase totalidade do seu valor.

É difícil, pois, evitar a violência ao falar de caraculos. A própria noção de ovelha local é uma categoria problemática. Nunca foi fácil para os concessionários europeus obter ovelhas locais em número suficiente para conseguir uma exploração comercialmente interessante. Além disso, os pastores locais sempre resistiram a vender as suas ovelhas, obrigando à importação de animais de outras paragens. Depois de várias tentativas frustradas com raças de outras zonas de Angola, houve que despender vastas somas de dinheiro para adquirir ovelhas do Tanganica, cuja cauda grossa, à semelhança da do caracul, garantia a sua sobrevivência nas exigentes condições do deserto (Garutti 1951).

Apesar de toda a retórica sobre as virtudes civilizadoras do sedentarismo sobre o nomadismo, a exploração de caraculos exigia a disponibilidade de mão-de-obra local para pastorear os rebanhos pelos milhares de hectares das propriedades. Criticando a pouca apetência dos kuvales para a pastorícia de ovinos e o seu costume de reservar essa atividade para as crianças, Santos Pereira não duvidou em sugerir que fosse o agente do curador dos indígenas da circunscrição a fornecer mão-de-obra, reproduzindo os esquemas de trabalho forçado comuns no mundo colonial português. ${ }^{16} \mathrm{Na}$ sua contabilidade, cada pastor indígena cuidaria de 100 ovelhas, pelo que, no longo prazo, estaríamos então a falar de 20.000 pastores mobilizados para a reserva do caracul. É bom ter presente que esta nunca era uma operação de reprodução fiel, pois a pastorícia passaria agora a ser uma atividade estandardizada, distinta das transumâncias dos gados kuvales. As deslocações entre as diferentes zonas das concessões eram afinal estabelecidas por um quadro de gestão de pastos que determinava os movimentos dos pastores e dos seus rebanhos.

Mas a presença de processos miméticos na história colonial do caracul de Angola tem a sua forma mais evidente nas casas construídas no posto para habitação dos pastores que formavam o "bairro indígena do PEC". ${ }^{17}$ Santos Pereira estava verdadeiramente orgulhoso de um novo modelo de cubata por ele desenvolvido, batizando os redondéis construídos com tijolo e argamassa de "estilo caracul". A sua grande originalidade estaria na substituição, nos

15 Para detalhes sobre a forma de funcionamento das explorações de caraculos, consultar as descrições de M. Santos Pereira (1953, 1959) e de Mario Garutti (1951).

16 Ver M. Santos Pereira, "Plano de acção para o desenvolvimento do caracul de Angola", Arquivo do Instituto Português de Apoio ao Desenvolvimento, 1957, p. 19.

17 Ver M. Santos Pereira, "Construções de estilo caracul: como construir economicamente casas circulares com tetos de tijolo", Arquivo do Instituto Português de Apoio ao Desenvolvimento (IPAD 16195), 1958. Cristiana Bastos explora neste mesmo dossiê da Etnográfica o conceito de mimese através da arquitectura dos hospitais-cubata (Bastos 2014). 


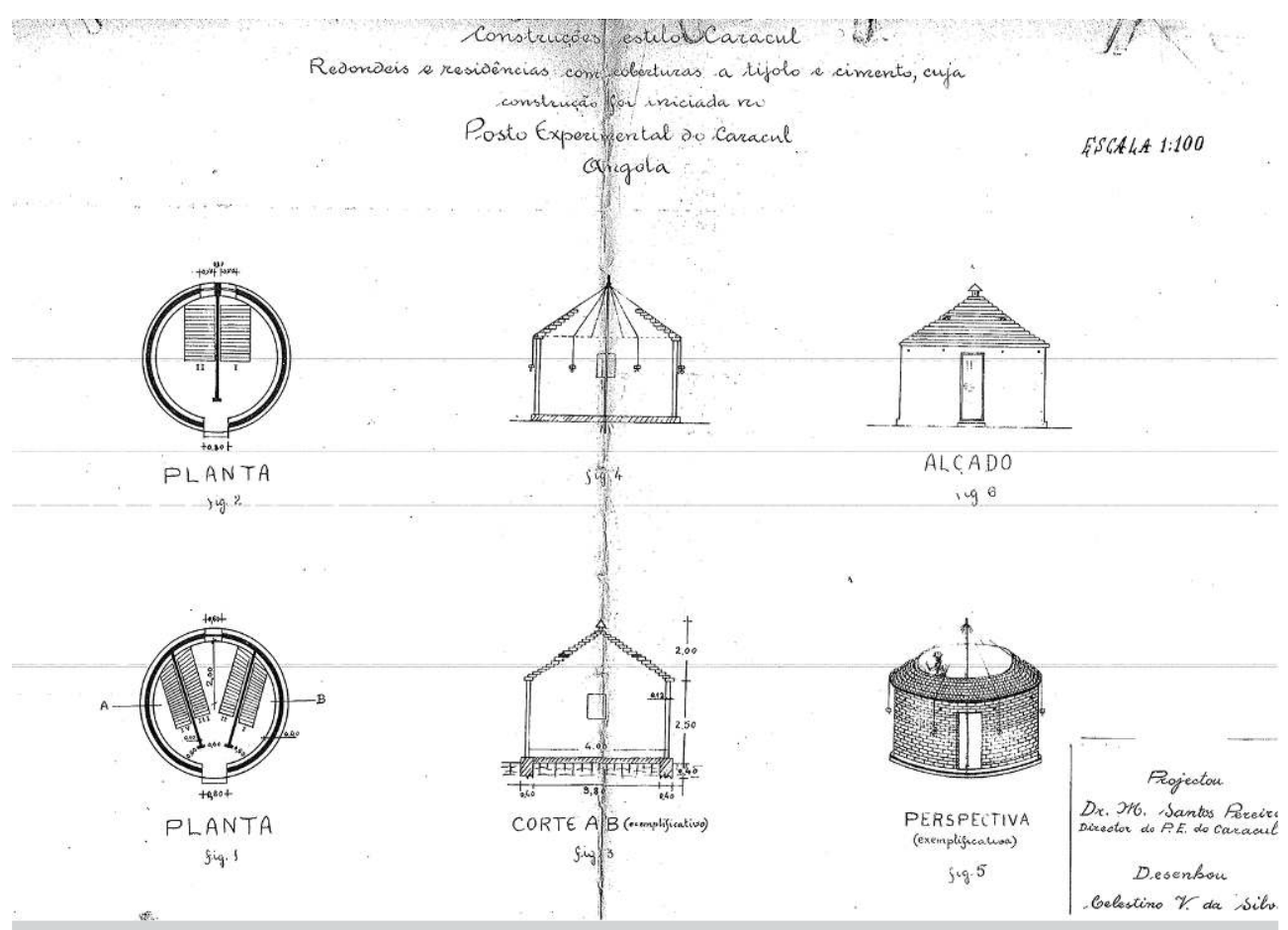

Figura 2 - Manuel dos Santos Pereira, "Construções estilo caracul: como construir economicamente casas circulares com tetos de tijolo", Posto Experimental do Caracul, julho de 1958. Fonte: Arquivo do IPAD (IPAD/MU/DGE/RRN/1548/16195).

tetos dos redondéis, do tradicional colmo por tijolos e cimento, aplicados estes em fiadas concêntricas cada vez mais apertadas, e para a construção dos quais "não se carecia de ferro, de suportes, de armações ou de moldes" ${ }^{18}$ O veterinário não se coibiu de desenvolver um processo estandardizado para a edificação destas cubatas estilo caracul, as quais, além de terem sido construídas nas diferentes concessões, foram também erigidas em Moçâmedes, onde se ergueu um "bairro indígena" todo em estilo caracul, inaugurado, como não poderia deixar de ser, a 28 de maio de 1958. O caráter uniforme dos redondéis escondia ainda três diferentes topologias de interiores: "sem divisão para pretos casados e já assimilados; uma divisória central para dois casais sem filhos; três divisões albergando quatro indígenas solteiros" ${ }^{19}$ Compare-se esta descrição sucinta com a complexidade de uma onganda, "a modalidade mais fixa de residência

18 M. Santos Pereira, "Construções de estilo caracul: como construir economicamente casas circulares com tectos de tijolo”, Arquivo do Instituto Português de Apoio ao Desenvolvimento (IPAD 16195), 1958, p. 7.

19 M. Santos Pereira, "Construções de estilo caracul: como construir economicamente casas circulares com tectos de tijolo”, Arquivo do Instituto Português de Apoio ao Desenvolvimento (IPAD 16195), 1958 , p. 8 . 
dos kuvale" (R. Carvalho 1997: 25). A antropologia, sobretudo da mão de Ruy Duarte de Carvalho, deu já boa conta das funções sociais mantidas por uma onganda de kuvales:

"cercados de rama de arbustos que podem atingir os $70 \mathrm{~m}$ de diâmetro e no interior dos quais o gado pernoita e se dispõem as casas, cónicas e baixas, e um cercado menor para os vitelos. Cada onganda abriga dois ou três grupos familiares que podem ser ou não parentes entre si e contar ou não com a presença dos filhos adultos, ou sobrinhos, ou outros dependentes, dos homens mais velhos que os chefiam e estabelecem desta forma entre si parcerias que implicam a exploração em conjunto do gado que mantêm sob a sua incidência imediata" (R. Carvalho 1997: 29).

O perímetro de uma onganda incluía também cemitérios e locais de culto. Percebe-se assim melhor o que acima referi como o empobrecimento operado pelo processo mimético - bem como a sua violência. A aparente sensibilidade local do veterinário responsável pelo PEC, expressa na criação do estilo caracul, oculta uma negação da sociabilidade kuvale, resumindo-se agora a esfera doméstica à oposição casado/solteiro e a condição de indígena à de assalariado de uma fazenda de colono branco.

\section{UMA CASA PORTUGUESA NO DESERTO DE MOÇÂMEDES}

À data em que Gilberto Freyre visitou o PEC, ainda este bairro não estava construído. Mas não custa imaginar as loas que Freyre poderia ter tecido às cubatas híbridas desenhadas por Santos Pereira, combinando as tradições locais com o engenho e a técnica europeias. O que, sim, já estava de pé quando Freyre visitou o PEC, era a casa do diretor, a qual demonstrava, segundo Freyre, "que era possível viver um português em Caracul em verdadeiro oásis":

"Tal era residência do diretor de Posto, toda cercada de trepadeiras, entre as quais uma latada com cachos de uvas tão lusitanamente frescas que à primeira vista parecem postiças... as parreiras rebentam em uvas gordas, junto à varanda das casas e ao alcance das mãos dos meninos e da própria gente grande mais saudosa de frutas e dos aromas de Portugal" (Freyre 1980 [1953]: 374).

Enquanto Santos Pereira cuidava da manutenção da pureza dos reprodutores caracul acumulando quilómetros na sua carrinha Chevrolet, a sua mulher servia "almoços magníficos, com a graça e dignidade de quem presidisse a um jantar de Lisboa ou no Porto” (Freyre 1980 [1953]: 375). Já muito foi escrito sobre os excessos de reprodução dos costumes da metrópole no espaço colonial, 
como aqueles praticados pela mulher de Santos Pereira e descritos por Freyre (Stoler 2002). Afinal, já Malinowski chamava a atenção na década de 1940 para o facto de "a comunidade de colonos brancos não ser de forma nenhuma uma réplica direta da comunidade da metrópole” (Malinowski 1966 [1945]). A mimese da vida portuguesa - materializada tanto na formalização excessiva dos atos quotidianos como na arquitetura "casa portuguesa" da residência do diretor com a sua varanda e latada -, mais do que transplantar Portugal para África, constitui um elemento de construção da "comunidade inventada" do colono branco (Anderson 1983). Esta "casa portuguesa ultramarina” (Milheiro 2012), na expressão dos técnicos do Gabinete de Urbanização Colonial responsáveis pelos projetos arquitetónicos de casas para colonos e para funcionários da administração colonial, era, como bem sublinhou Ana Vaz Milheiro, mais portuguesa que a própria “casa portuguesa” na metrópole (Milheiro 2012). O posto juntava assim à mimese por defeito do "bairro indígena" a mimese por excesso da metrópole, a qual era destinada, como afirmava o próprio Santos Pereira, a "reproduzir criadores de caraculos" (Pereira 1959). O posto não era mais, pois, do que o primeiro núcleo de um projeto de colonização que ocuparia um território com extensão semelhante ao do Portugal metropolitano e que estaria destinado a ser mais português que Portugal.

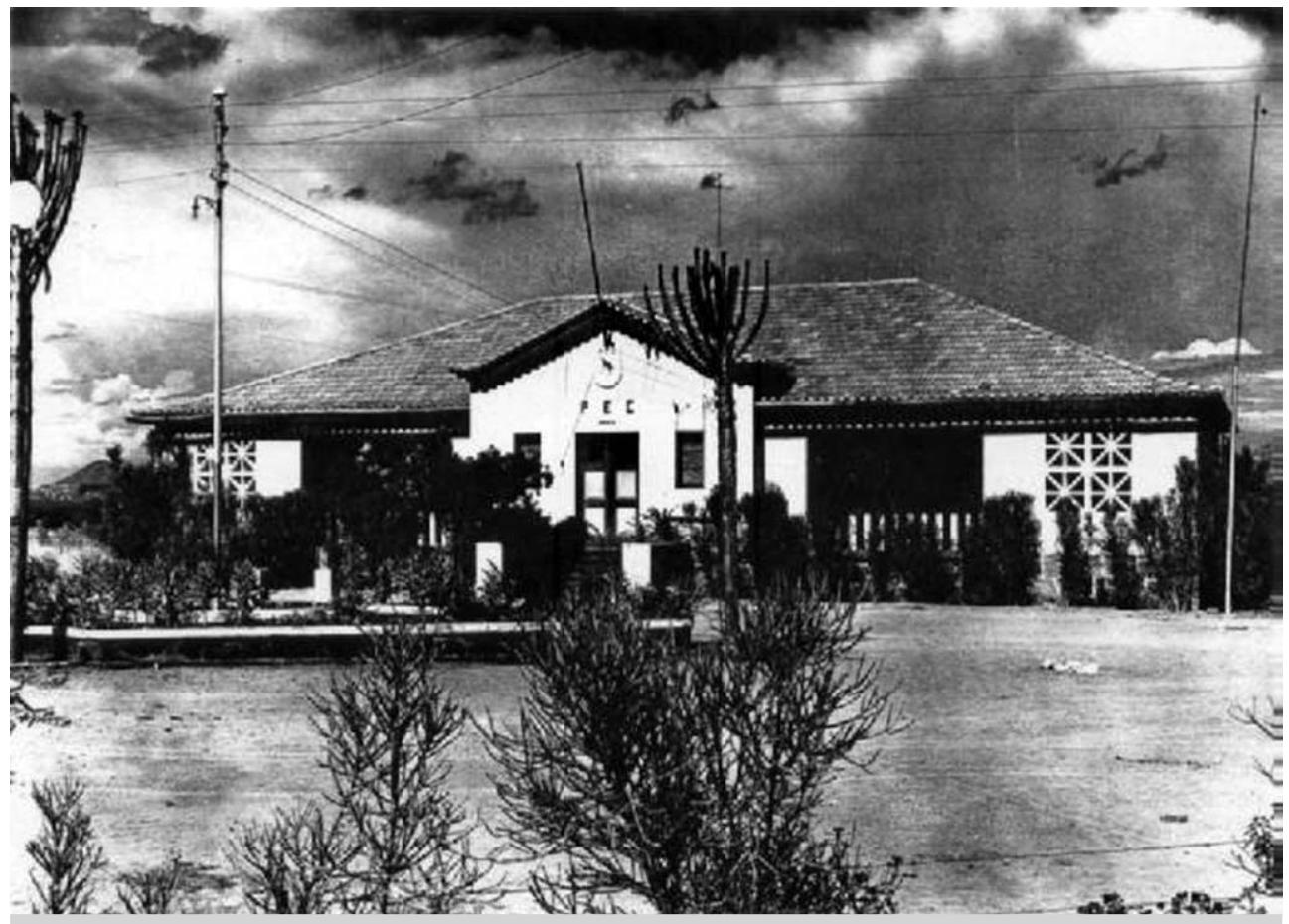

Figura 3 - "Casa do diretor", Posto Experimental do Caracul, c. 1960. Fonte: Arquivo do IPAD (IPAD/MU/DGE/RRN/1548/06127). 
A reprodução de caraculos equivalia então à reprodução de colonos. A vida dos povoadores brancos na reserva colonial do caracul não estava menos organizada em função da reprodução animal do que a vida dos kuvales junto das suas manadas de bois. Olhar para as técnicas de reprodução dos caraculos não serve assim apenas de metáfora da vida social colonial e para estabelecer uma correspondência de ordem formal entre falta de hibridismo animal e falta de miscigenação humana. Manter uma fazenda de caraculos exigia seguir não apenas os preceitos zootécnicos difundidos por Santos Pereira, mas seguir, também, a construção de um espaço colonial específico, exemplificado modelarmente pelo PEC: um espaço constituído pela casa do diretor, pelo "bairro indígena", e por pastagens segmentadas a arame farpado em função da cuidada gestão de forragens. Na aparência, o Posto Experimental do Caracul parecia ser respeitador dos costumes locais: cubatas limpas e ordenadas e nativos empregados no cuidado de animais, mas seguindo agora os ensinamentos da genética europeia em vez das suas complicadas genealogias. Mas basta raspar um pouco esta superfície de aparências e a mimese alegre de Freyre toma os tons mais escuros da mimese colonial de Taussig. Kuvales roubados do seu gado e exterminados por serem tidos como violentos selvagens e ladrões de gado; "bairros indígenas" à imagem de ongandas, mas que não são mais que depósitos baratos de mão-de-obra assalariada; fazendas imensas de caracul que rasgam a paisagem a arame farpado, e entre cujas fiadas os kuvales têm direito a conduzir o seu gado, mantendo assim vivo o mito do respeito português pelo outro. Percebe-se então que o luso-tropicalismo visionado por Freyre, ao contrário do que este pretendia, se sustenta não sobre processos de hibridação, mas sim sobre um triplo mimetismo: de outras experiências imperiais europeias materializadas nas ovelhas caracul importadas da Alemanha; da sociabilidade local reproduzida de forma estandardizada no "bairro indígena" do posto; e, por fim, da metrópole, traduzida na casa portuguesa tropical do diretor. O Posto Experimental do Caracul lembra-nos que tanto o "luso" como o "tropicalismo" são afinal produtos da operação de modos vários de mimese colonial. 


\section{BIBLIOGRAFIA}

AGU, 1959, O Caracul. Lisboa, Agência Geral do Ultramar.

ALMEIDA, João de, 1912, Sul de Angola: Relatório de Um Governo de Distrito (1908-1910). Lisboa, Tip. Anuário Comercial.

ANDERSON, Benedict, 1983, Imagined Communities: Reflections on the Origin and Spread of Nationalism. Londres, Verso.

BASTOS, Cristiana, 1998, “Tristes trópicos e alegres luso-tropicalismos: das notas de viagem em Lévi-Strauss e Gilberto Freyre”, Análise Social, 33 (146-147): 415-432.

BASTOS, Cristiana, 2011, "Ilhas, planaltos e travessias: os fluxos de madeirenses entre plantações e colónias”, em As Ilhas da Europa, a Europa das Ilhas. Funchal, Centro de Estudos de História do Atlântico, 187-196.

BASTOS, Cristiana, 2014, "No género de construções cafreais": o hospital-palhota como projecto colonial, Etnográfica, 18 (1): 185-208.

BHABHA, Homi, 1984, "Of mimicry and man: the ambivalence of colonial discourse", October, 28: 125-133.

BONNEUIL, Christophe, 1999, "Penetrating the natives: peanut breeding, peasants and the colonial State in Senegal (1900-1950)", Science Technology \& Society, 4 (2): 273-302.

BONNEUIL, Christophe, 2000, "Development as experiment: science and State building in late colonial and postcolonial Africa, 1930-1970”, Osiris, 15: 258-281.

BRAVENBOER, Brenda, 2007, Karakul: Gift from the Arid Land, 1907-2007. Windhoek, Karakul Board of Namibia and Karakul Breeders' Society of Namibia.

CARSON, Cathryn, 2010, "Science as instrumental reason: Heidegger, Habermas, Heisenberg", Continental Philosophy Review, 42: 483-509.

CARVALHO, Eduardo Cruz de, 1974, "Traditional and modern patterns of cattle in Southwestern Angola: a critical evaluation from pastoralism to ranching", The Journal of Developing Areas, 8 (2): 199-226.

CARVAlHo, Ruy Duarte, 1997, Aviso à Navegação: Olhar Sucinto e Preliminar sobre os Pastores Kuvale da Província do Namibe com Um Relance sobre as Outras Sociedades Agropastoris do Sudoeste de Angola. Luanda, Instituto Nacional do Livro e do Disco.

CARVAlho, Ruy Duarte, 1999, Vou Lá Visitar Pastores: Exploração Epistolar de Um Percurso Angolano (1992-1997). Lisboa, Cotovia.

CASTElo, Cláudia, 2007, Passagens para África: O Povoamento de Angola e Moçambique com Naturais da Metrópole (1920-1974). Porto, Afrontamento.

ClarenCE-SMITH, William Gervase, 1979, Slaves, Peasants, and Capitalists in Southern Angola, 1840-1926. Cambridge, Cambridge University Press.

EVANS-PRITCHARD, Edward E., 1965 [1940], The Nuer: A Description of the Modes of Livelihood and Political Institutions of a Nilotic People. Oxford, Oxford University Press.

FEIO, Mariano, 1998, As Causas do Fracasso da Colonização Agrícola de Angola. Lisboa, Ministério da Ciência e Tecnologia/Instituto de Investigação Científica Tropical.

FIGUEIREDO, Salvador de, 2006, Angola, O Último Café. Torres Vedras, ABC - Impressão Côr de J. Grilo.

FOnSECA, Ana Sofia, 2009, Angola, Terra Prometida: A Vida que os Portugueses Deixaram. Lisboa, Esfera dos Livros.

FRANKLIN, Sarah, 2007, Dolly Mixtures: The Remaking of Genealogy. Durham, Duke University Press. 
FREYRE, Gilberto, 1980 [1953], Aventura e Rotina: Sugestões de Uma Viagem à Procura das Constantes Portuguesas de Carácter e Acção. Lisboa, Livros do Brasil.

GARUTTI, Mario, 1951, "Relazione sul PEK: osservazioni del Dott. Mario Garutti”, Arquivo do Istituto Agricola per l'Oltroemare, Fasc. 1027.

GERWARTH, Robert, e Stephan MALINOWSKI, 2009, "Hannah Arendt's ghosts: reflections on the disputable path from Windhoek to Auschwitz", Central European History, 42 (2): 279-300.

GOULD, Isabel Ferreira, 2008, "Decanting the past: Africa, colonialism, and the new Portuguese novel”, Luso-Brazilian Review, 45: 182-197.

GRIFFITHS, Tom, 1997, Ecology and Empire: Environmental History of Settler Societies. Seattle, University of Washington Press.

HARAWAY, Donna J., 2008, When Species Meet. Minneapolis, University of Minnesota Press. KROGH, D.C., 1955, "Economic aspects of the karakul industry in South West Africa", South African Journal of Economics, 23 (2): 99-1 13.

MALINOWSKI, Bronislaw, 1966 [1945], "Dynamics of cultural change", em Immanuel Wallerstein, Social Change: The Colonial Situation. Nova Iorque, John Wiley and Sons, $11-24$.

MEDeIRos, Carlos Alberto, 1976, A Colonização das Terras Altas da Huíla (Angola): Estudo de Geografia Humana. Lisboa, Centro de Estudos Geográficos.

MELO, Daniel, 2001, Salazarismo e Cultura Popular (1933-1958). Lisboa, Imprensa de Ciências Sociais.

MilHeiro, Ana Vaz, 2012, Nos Trópicos sem Le Corbusier: Arquitectura Luso-Africana no Estado Novo. Lisboa, Relógio d'Água.

NETZ, Reviel, 2004, Barbed Wire: An Ecology of Modernity. Middletown, CT, Wesleyan University Press.

PÉLISSIER, René, 1997, História das Campanhas de Angola: Resistência e Revoltas, 1845-1941. Lisboa, Estampa.

PereirA, M. Santos, 1953, Plano de Fomento do Karakul de Angola. Lisboa, s/ed.

PEReira, M. Santos, 1955, O Que Pode Valer o Caracul na Economia e Ocupação de Angola. Lisboa, Centro de Estudos Económicos.

PEREIRA, M. Santos, 1959, "Situação do caraculo Angolano", Boletim Geral do Ultramar, 406: $27-56$.

ROQUE, Ricardo, 2014, “Seria preciso que a selvageria se me pegasse': Afonso de Castro e a "festa das cabeças" em Timor colonial", Etnográfica, 18 (1): 159-184.

SARAIVA, Tiago, 2013, "The production and circulation of standardized Karakul sheep and frontier settlement in the empires of Hitler, Mussolini, and Salazar", em Dolly Jørgensen, Finn Arne Jørgensen e Sara Pritchard (orgs.), New Natures: Joining Environmental History with Science and Technology Studies. Pittsburgh, University of Pittsburgh Press, 181-203.

SCHMOKEL, Wolfe W., 1985, "The myth of the white farmer: commercial agriculture in Namibia, 1900-1983”, The International Journal of African Historical Studies, 18 (1): 93-108.

STOECKER, Helmuth, 1986, German Imperialism in Africa: From the Beginnings until the Second World War. Londres, Hurst \& Co.

STOLER, Ann Laura, 2002, Carnal Knowledge and Imperial Power: Race and the Intimate in Colonial Rule. Berkeley, University of California Press. 
TAUSSIG, Michael, 1987, Shamanism, Colonialism, and the Wild Man: A Study in Terror and Healing. Chicago, The University of Chicago Press.

TAUSSIG, Michael, 1993, Mimesis and Alterity: A Particular History of the Senses. Nova Iorque, Routledge.

VIEIRA, António da Silva, 1967, Trigo de Morais Segundo Alguns Depoimentos. Lisboa, Agência Geral do Ultramar.

WEIGEND, Guido G., 1985, "German settlement patterns in Namibia", Geographical Review, 75 (2): 156-169.

ZIMMERER, Jürgen, 2005, "Annihilation in Africa: the "race war"” em "German Southwest Africa (1904-1908) and its significance for a global history of genocide", Bulletin of the German Historical Institute in Washington, DC, 37: 51-57.

ZIMMERER, Jürgen, 2011 , Von Windhuk nach Auschwitz?: Beiträge zum Verhältnis von Kolonialismus und Holocaust. Münster, LIT Verlag. 